\title{
Challenges and Strategies in the Synthesis of Mesoporous Alumina Powders and Hierarchical Alumina Monoliths
}

\author{
Sarah Hartmann, Alexander Sachse and Anne Galarneau * \\ Institut Charles Gerhardt Montpellier, UMR 5253 CNRS/UM2/ENSCM/UM1, \\ ENSCM 8 Rue de l'Ecole Normale, 34296 Montpellier Cedex 5, France; \\ E-Mails: s.j.hartmann@web.de (S.H.); alexandersachse82@gmail.com (A.S.) \\ * Author to whom correspondence should be addressed; E-Mail: anne.galarneau@enscm.fr; \\ Tel.: +33-4-6716-3468; Fax: +33-4-6716-3470.
}

Received: 14 December 2011; in revised form: 13 February 2012 / Accepted: 13 February 2012 / Published: 20 February 2012

\begin{abstract}
A new rapid, very simple and one-step sol-gel strategy for the large-scale preparation of highly porous $\gamma-\mathrm{Al}_{2} \mathrm{O}_{3}$ is presented. The resulting mesoporous alumina materials feature high surface areas $\left(400 \mathrm{~m}^{2} \mathrm{~g}^{-1}\right)$, large pore volumes $\left(0.8 \mathrm{~mL} \mathrm{~g}^{-1}\right)$ and the $\gamma-\mathrm{Al}_{2} \mathrm{O}_{3}$ phase is obtained at low temperature $\left(500^{\circ} \mathrm{C}\right)$. The main advantages and drawbacks of different preparations of mesoporous alumina materials exhibiting high specific surface areas and large pore volumes such as surfactant-nanostructured alumina, sol-gel methods and hierarchically macro-/mesoporous alumina monoliths have been analyzed and compared. The most reproducible synthesis of mesoporous alumina are given. Evaporation-Induced Self-Assembly (EISA) is the sole method to lead to nanostructured mesoporous alumina by direct templating, but it is a difficult method to scale-up. Alumina featuring macro- and mesoporosity in monolithic shape is a very promising material for in flow applications; an optimized synthesis is described.
\end{abstract}

Keywords: mesoporous alumina; high surface area alumina; alumina monolith; hierarchical porosity; nanostructured alumina; catalyst support

\section{Introduction}

The industrial interest of alumina is highlighted by its intensive use as catalyst or as catalytic support materials for the petroleum refinement and as automobile emission controller [1,2]. The use of 
alumina can be ascribed to both high thermal stability and moderate Lewis acidity as well as to the fact it is a rather inexpensive material. $\gamma-\mathrm{Al}_{2} \mathrm{O}_{3}$ is commonly used as support for nanocrystal of $\mathrm{MoS}_{2}$ doped with $\mathrm{Co}$ or $\mathrm{Ni}$ for hydrodesulfurization (HDS) processes [3]. Recently, high surface area nanostructured alumina has allowed to increase the catalytic behavior of HDS catalysts [4]. Therefore it is important to develop strategies to design simple, reproducible and easy to scale-up procedures leading to high surface area, high pore volume and high pore size alumina by simple methods to be implemented in industrial processes.

The introduction of defined porosity within bulk alumina is requested for many other catalytic applications besides oil refining and sorption applications [5,6]. This is mainly due to the fact that the presence of mesopores enhances the diffusion properties of the material and increases the amount of accessible active sites [7]. The preparation of porous alumina with well-defined mesopores and high surface areas has been reported by several groups by the use of surfactant-directing agents $[8,9]$. The group of Zhao recently extended the synthesis of nanostructured mesoporous alumina by the evaporation-induced self-assembly (EISA) with tailorable structure and pore size assisted by the organic swelling agent trimethylbenzene [10]. Furthermore, the nanocasting method gives a large spectrum of possible mesoporous aluminas by the diversity of hard templates available [11]. These synthetic routes are rather time consuming as it uses a double replica route through a carbon phase and rely on multi-step synthesis and are thus difficult to scale up. For many industrial applications very narrow pore size distributions are not necessary. Several attempts in the literature describe the synthesis of porous alumina with wide size distribution of mesopores [12]. The group of Satcher developed a simple synthetic route to mesoporous alumina by the use of epoxides as gelation initiators in the preparation of sol-gel materials [13]. Yao et al. have fabricated amorphous alumina by a sol-gel process using ultrasound to provide energy [14].

The preparation of aluminas with hierarchical porosity with meso- and macropores have attracted a great deal of attention for catalytic applications, as pores on different length scales can assume diverse functions such as high dispersion of active site and high mass transfer [15]. Dacquin et al. [16] have for example shown the fabrication of macro-mesoporous alumina by combining surfactant and latex spheres (300-400 nm) templating methods. However the macropore sizes in combination with a delicate alumina skeleton seem to limit their applicability as stationary phases in catalysis in flow, as the macropore size reduces the mass transfer within the monolith and the backbone probably can not withstand the resulting back pressure. Hierarchical systems such as macro and mesoporous monoliths with large macropores ( 3 microns) based on silica or alumina-lined silica have recently shown their potentiality as catalytic flow microreactors for the fine chemical production with low pressure drop ( $<0.5$ bars) [17-19]. The morphological control of hierarchical alumina monoliths thus gives rise to a new class of promising candidates for application as catalytic microreactors.

The aim of this publication is hence to compare the synthetic routes of the literature and to propose the easiest and the most reproducible synthesis to produce mesoporous alumina with the desired properties. The selected synthetic routes present the formation of ordered and disordered mesoporous alumina powders featuring large mesopores, high surface areas and large pore volumes, as well as the synthetic strategies for the achievement of hierarchical alumina monoliths with large macropores efficient for continuous flow applications. Furthermore, a new synthetic route will be presented for the 
formation of mesoporous alumina by a very simple, one step sol-gel process resulting in a highly porous $\gamma-\mathrm{Al}_{2} \mathrm{O}_{3}$ phase obtained at low temperature.

\section{Results and Discussion}

\subsection{Nanostructured Mesoporous Amorphous $\mathrm{Al}_{2} \mathrm{O}_{3}$ Powders}

In 2008, Yuan et al. were among the first to present a facile synthesis procedure for the preparation of nanostructured mesoporous $\mathrm{Al}_{2} \mathrm{O}_{3}$ powders [20]. By employing amphiphilic block copolymers such as Pluronic ${ }^{\circledR}$ P123 and F127 formed of ethylene-oxide (EO) and propyleneoxide (PO) groups $\left(\mathrm{EO}_{20} \mathrm{PO}_{70} \mathrm{EO}_{20}\right.$ and $\mathrm{EO}_{100} \mathrm{PO}_{65} \mathrm{EO}_{100}$, respectively) in an evaporation-induced self-assembly process (EISA), highly ordered mesoporous organic-inorganic nanocomposites were obtained under controlled evaporation at $60{ }^{\circ} \mathrm{C}$. Several groups have tried to use P123 as structuring agent for the nanostructuration of alumina $[4,21,22]$, however without the use of EISA process no ordered alumina phases have been obtained.

Figure 1. Schematic depiction of the formation of the nanostructured mesoporous alumina via the evaporation-induced self-assembly mechanism (EISA). The TEM image was taken from our own preparation (see experimental section) of an as-synthesized alumina material showing the 2D-hexagonally arrangement of mesopores (calcined at $400{ }^{\circ} \mathrm{C}$ for $4 \mathrm{~h}$ ).

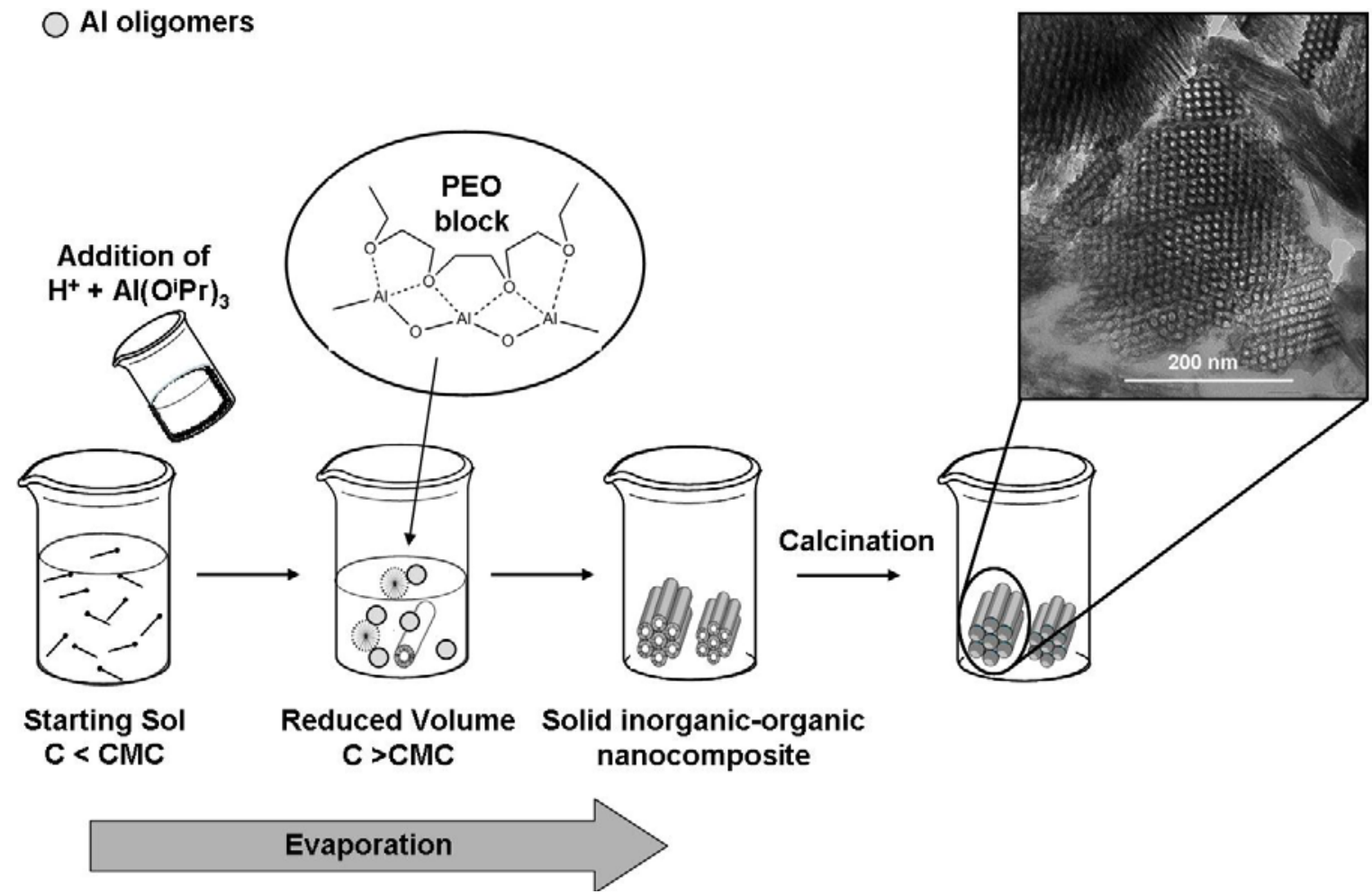

Among the different proposed EISA processes [10,20,23,24], the one proposed by Yuan et al. [20] seems to be the simplest and the fastest to get mesoporous alumina powder. In this acidic EISA process, it is assumed that the multivalent hydrolysed and partly condensed Al species are preferentially assembled in the ethylene oxide blocks of the structure-directing co-polymer via weak coordination bonds [25]. As concentrated acids are employed as catalysts, this association is even 
enhanced by hydrogen bonding, allowing a systematic growth of the Al oligomers in the hydrophilic domains, which finally results in the formation of a mesoscopically ordered inorganic-organic nanocomposite. In the original publication of Yuan et al. [20], the recipe for the synthesis of nanostructured alumina is not clearly formulated, as a wide range of concentrations for each reactant and of acids is given. Other recipes for the EISA process have been formulated by the groups of Jaroniec and Wilson [26,27]. We successfully obtained a nanostructured mesoporous amorphous alumina (Figure 1) by following the recipe we present in the experimental section. It is important to avoid washing or liquid extraction before drying is completed, as the organic template prevents the mesoporous structure to collapse during the drying step. Only after a substantial drying at $60{ }^{\circ} \mathrm{C}$ leading to the solidification of the amorphous alumina phase, the calcination at $400{ }^{\circ} \mathrm{C}$ can be proceed and a free accessible 2D-hexagonally arranged mesopore system is achieved (Figure 2).

Figure 2. (A) Nitrogen sorption isotherm at $77 \mathrm{~K}$ of hexagonal mesoporous alumina with amorphous walls; (B) corresponding TEM image of the 2D-hexagonally arranged mesopore system; (C) Small X-Ray Diffraction recorded in the range showing the hexagonal arrangement; (D) ${ }^{27}$ Al MAS NMR spectra recorded at a spinning rate of $10 \mathrm{kHz}$.
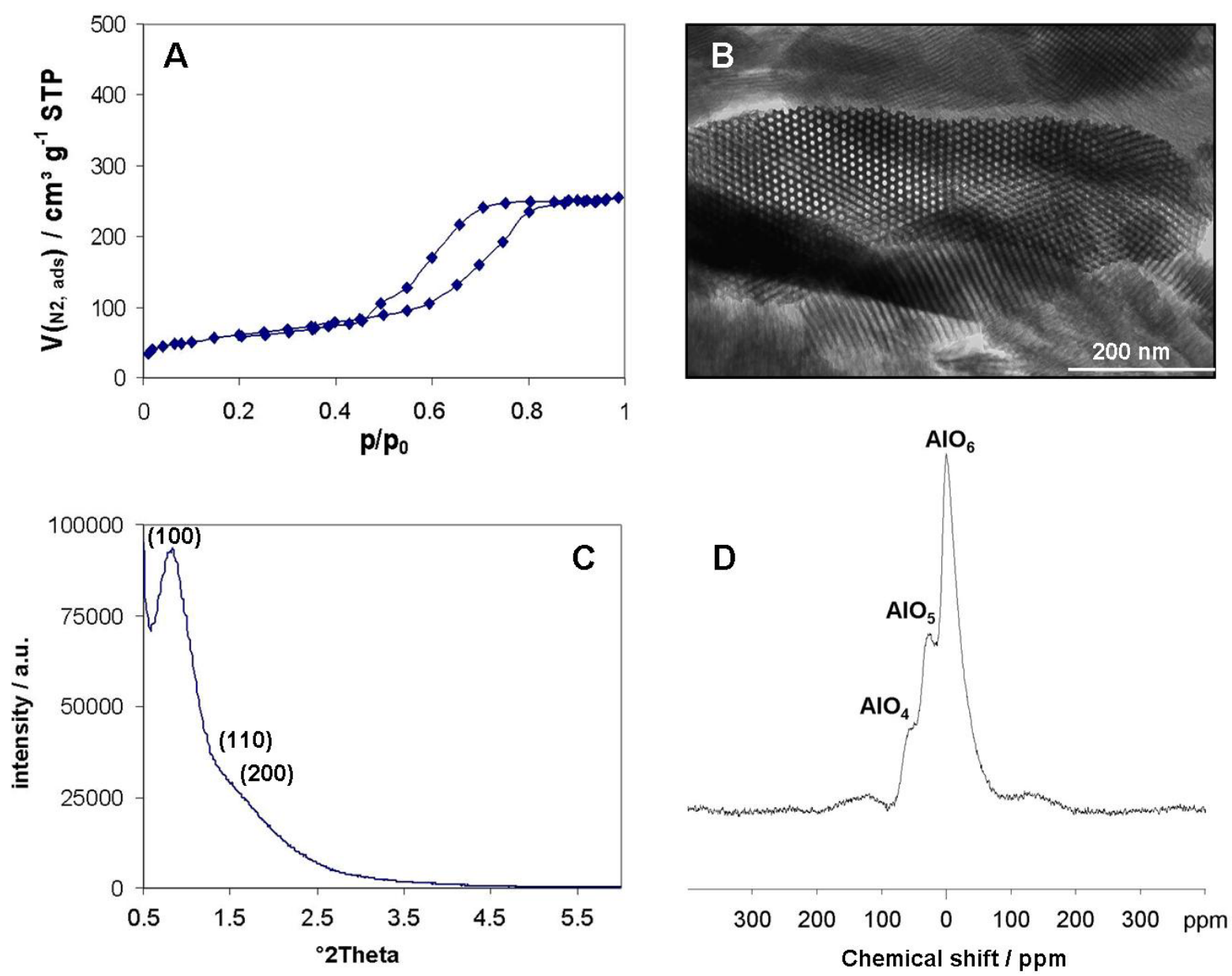

Thermogravimetric analysis confirmed that after calcination at $400{ }^{\circ} \mathrm{C}$ the structure-directing agents have been removed. Via this synthesis procedure nanostructured 2D-hexagonally mesoporous $\mathrm{Al}_{2} \mathrm{O}_{3}$ powders were synthesized featuring specific surface areas of $197 \mathrm{~m}^{2} \mathrm{~g}^{-1}$, pore volume of $0.38 \mathrm{~mL} \mathrm{~g}^{-1}$ and mesopore diameter of $8.6 \mathrm{~nm}$ by employing $\mathrm{EO}_{20} \mathrm{PO}_{30} \mathrm{EO}_{20}$ as structure-directing agent and 
concentrated $\mathrm{HNO}_{3}$ as acidic catalyst (Figure 2A). Even though this synthesis was conducted in acidified ethanolic solution without addition of water, the water contents in nitric acid and in ethanol are sufficient to induce the hydrolysis of the $\mathrm{Al}(\mathrm{O} i \mathrm{Pr})_{3}$ precursor. As can be seen from the X-ray diffraction pattern (Figure 2C) and the TEM image (Figure 2B), the 2D-hexagonal ordering of the mesopore system is highly evolved and XRD pattern shows a d-spacing $d_{100}$ of $10.8 \mathrm{~nm}$. The diffraction pattern in the wide-angle range indicates that after calcination at $400{ }^{\circ} \mathrm{C}$ the pore walls are completely amorphous. The corresponding ${ }^{27} \mathrm{Al}$ MAS NMR spectra (Figure 2D) of the sample shows three resonance signals at 0,29 and $62 \mathrm{ppm}$ which can be related to the octahedral coordinated $\mathrm{AlO}_{6}$, the pentahedral coordinated $\mathrm{AlO}_{5}$ and the tetrahedral coordinated $\mathrm{AlO}_{4}$ sites in the alumina matrix. Penta-coordinated alumina is often associated to the presence of amorphous alumina phase, which is the case in this preparation. The penta-coordinated alumina disappeared in the benefit of hexa-coordinated alumina for a calcination at $900{ }^{\circ} \mathrm{C}$ giving the $\gamma-\mathrm{Al}_{2} \mathrm{O}_{3}$ phase. These results are in accordance with the literature $[4,10,20]$ except that lower surface areas (200 instead of $\left.300-400 \mathrm{~m}^{2} \mathrm{~g}^{-1}\right)$ and pore volumes $\left(0.4\right.$ instead of $\left.0.8 \mathrm{~mL} \mathrm{~g}^{-1}\right)$ have been obtained for a similar pore size.

Even if this synthesis is the more promising route to synthesized nanostructured mesoporous alumina, drawbacks have been discerned for this synthesis procedure that are: (1) smaller pore volumes and specific surface areas than expected $\left(200 \mathrm{~m}^{2} \mathrm{~g}^{-1}\right.$ and $\left.0.4 \mathrm{~mL} \mathrm{~g}^{-1}\right)$; (2) a large amount of organics to be eliminated as as-synthesized alumina features $70 \mathrm{wt} \%$ of organics, resulting in product yields below 30\%; (3) the amorphous nature of the resulting alumina phase (high temperatures of $>800{ }^{\circ} \mathrm{C}$ are necessary to obtain the $\gamma-\mathrm{Al}_{2} \mathrm{O}_{3}$ phase); and (4) difficulty to scale-up. Indeed for the development of this synthesis, the control of the EISA synthesis parameters such as humidity, temperature as well as the recipient volume to surface ratio in which the sol is evaporated are crucial, which makes it difficult to scale up the batch sizes for this procedure.

\subsection{Disordered Mesoporous $\gamma-\mathrm{Al}_{2} \mathrm{O}_{3}$ Powders}

If the desired application does not require a well-ordered mesoporous $\mathrm{Al}_{2} \mathrm{O}_{3}$ phase, as for theoretical study for instance, the synthesis of disordered mesoporous alumina materials based on sol-gel methods can be more convenient and efficient. In contrast to the previous synthesis that is difficult to scale-up via evaporation-induced self-assembly and requires an expensive structure-directing agent such as Pluronic P123, the synthesis of disordered mesoporous $\mathrm{Al}_{2} \mathrm{O}_{3}$ by careful sol-gel methods based on alumina hydrolysis control ([4] and references therein) leads to high surface area $\left(\sim 350 \mathrm{~m}^{2} \mathrm{~g}^{-1}\right)$ and high pore volume $\left(\sim 0.8 \mathrm{~mL} \mathrm{~g}^{-1}\right)$ mesoporous alumina which are much more easily scalable. Among the possible sol-gel methods, we have developed a new, one-step, easy and fast synthesis to obtain disordered mesoporous $\gamma-\mathrm{Al}_{2} \mathrm{O}_{3}$ at low temperature $\left(500{ }^{\circ} \mathrm{C}\right)$ by using 2-butoxyethanol as solvent and as controlling agent for the $\mathrm{Al}(\mathrm{Osec} \mathrm{Bu})_{3}$ hydrolysis and a small quantity of dodecylamine to speed up the synthesis leading to a rapid precipitate of alumina powder. 
Figure 3. Synthesis route for the rapid preparation of disordered mesoporous $\gamma-\mathrm{Al}_{2} \mathrm{O}_{3}$.

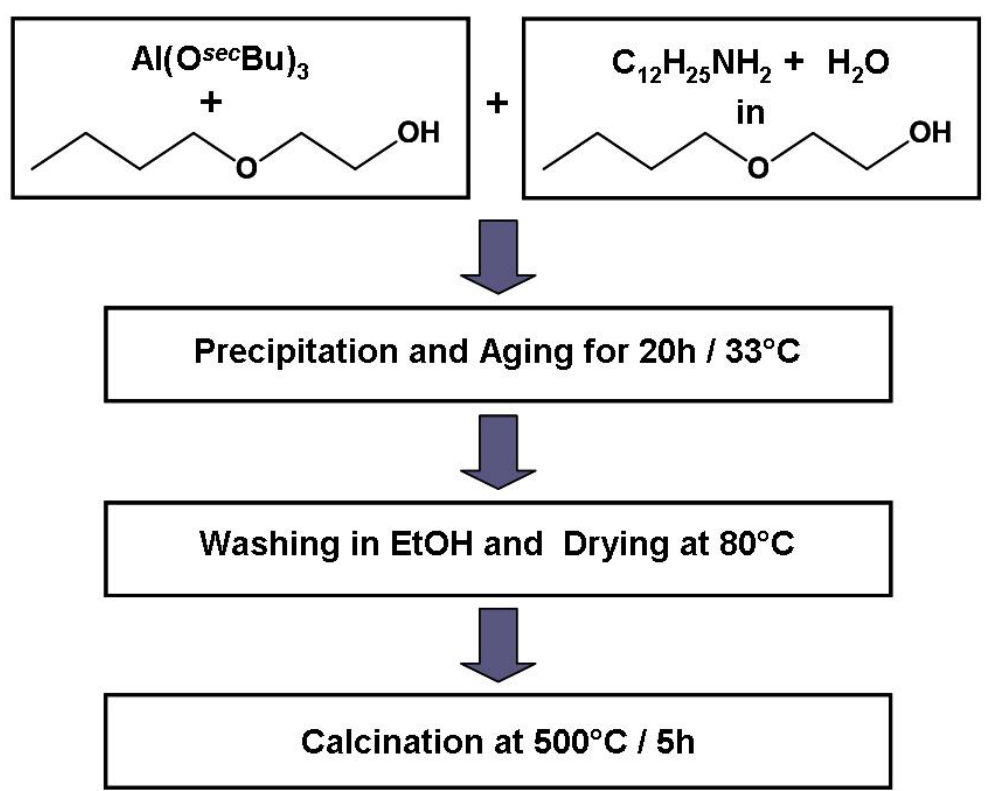

The water and dodecylamine containing solution is added drop-wise within 20 min under vigorous stirring. With the addition of the first drops, hydrolysis and condensation reactions lead to an instant gelation of the system. The gel is only destroyed by further addition of the aqueous solution resulting in the precipitation of alumina which is then aged for $20 \mathrm{~h}$ at $33{ }^{\circ} \mathrm{C}$. After washing in ethanol and drying at $80{ }^{\circ} \mathrm{C}$ the obtained powder consists of an amorphous alumina phase, which is then transformed into a semi-crystalline $\gamma-\mathrm{Al}_{2} \mathrm{O}_{3}$ phase by calcination at $500^{\circ} \mathrm{C}$ for $5 \mathrm{~h}$ as can be seen from the XRD pattern in Figure 4.

This mesoporous alumina material combines its crystalline attributes of the $\gamma-\mathrm{Al}_{2} \mathrm{O}_{3}$ phase with high specific surface areas of $338 \mathrm{~m}^{2} \mathrm{~g}^{-1}$, high pore volumes of $1.1 \mathrm{~mL} \mathrm{~g}^{-1}$ and large mesopore sizes of $11 \mathrm{~nm}$, which makes it a suitable candidate as inorganic support material for heterogeneous catalysis (Figure 4A). ${ }^{27} \mathrm{Al}$ MAS NMR shows the sole presence of tetrahedral and octahedral coordinated aluminium species as expected for a crystalline alumina phase. This procedure not only has proven to be a highly reproducible synthesis but also features less organics to be treated, as only $30 \mathrm{wt} \%$ of organics are present in the as-synthesized "sol-gel" alumina resulting in a $70 \%$ yield with respect to mass. 
Figure 4. (A) Nitrogen sorption isotherms at $77 \mathrm{~K}$ of mesoporous disordered $\gamma-\mathrm{Al}_{2} \mathrm{O}_{3}$ phase calcined at $500{ }^{\circ} \mathrm{C}$; (B) TEM image showing the fibrillar morphology of the material; (C) XRD pattern showing the peaks assigned to the $\gamma-\mathrm{Al}_{2} \mathrm{O}_{3}$ phase; (D) ${ }^{27} \mathrm{Al}$ MAS NMR spectra for which penta-coordinated $\mathrm{Al}$ sites are absent as expected for a crystalline alumina phase.
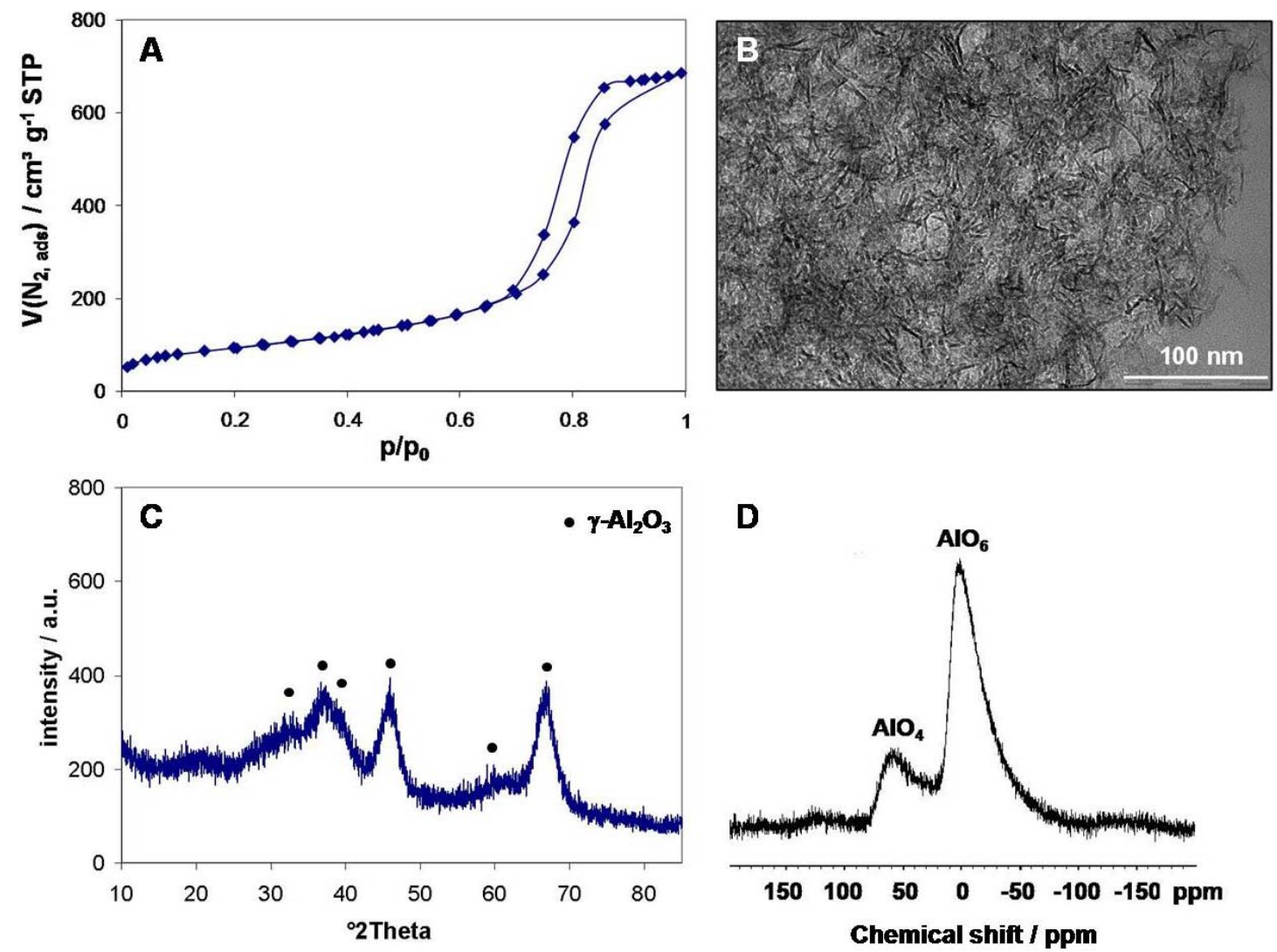

\subsection{Hierarchical Macro-/Mesoporous $\mathrm{Al}_{2} \mathrm{O}_{3}$ Monoliths}

To perform catalysis under continuous flow condition, alumina should be obtained as monoliths with hierarchical pore structure as for silica [17,19]: large macropores $(>1 \mu \mathrm{m})$ for high mass transfer with low drop pressure and high specific surface areas for a good dispersion of active sites. To our knowledge, the only procedures affording alumina with large macropore suitable for continuous flow applications have been proposed by the groups of Yuan and Nakanishi [28,29]. The synthesis developed in the Nakanishi group is based on a phase separation named spinodal decomposition between an alumina/polyethylene oxide (PEO) phase and an aqueous/PEO phase. In contrast to the previous sol-gel methods described for the syntheses of alumina powders, the preparation of alumina monoliths with hierarchical porosity (macro- and mesoporosity) demands a perfect control of parameters such as temperature, $\mathrm{H}_{2} \mathrm{O}$ content and $\mathrm{pH}$. The exactitude of these parameters is crucial to control the hydrolysis and condensation reactions and to avoid precipitation. Based on this synthesis procedure [28], the employment of an acidic aluminium salt such as $\mathrm{AlCl}_{3} \cdot 6 \mathrm{H}_{2} \mathrm{O}$ in ethanol/water mixture instead of an aluminium alkoxide precursor helps to avoid the rapid hydrolysis and condensation reactions due to formation of sole $\left[\mathrm{Al}\left(\mathrm{H}_{2} \mathrm{O}\right)_{6}\right]^{3+}$ at $\mathrm{pH}$ values below 3 [30]. However, for a sufficient prevention of the alumina condensation, we have chosen to mix the ionic aluminium 
precursor $\left[\mathrm{Al}\left(\mathrm{H}_{2} \mathrm{O}\right)_{6}\right]^{3+}$ with the $\mathrm{PEO} / \mathrm{EtOH} / \mathrm{H}_{2} \mathrm{O}$ solution under ice-cooled conditions before transferring the mixture into an oil-bath at $25{ }^{\circ} \mathrm{C}$ shortly before addition of the proton scavenger, propylene oxide, which will start the condensation and induce the phase separation.

Upon introduction of the proton scavenger, the $\mathrm{pH}$ is increased, thus shifting the equilibrium of the hydrolysis reaction to the product side (Scheme 1). Via subsequent condensation (olation and/or oxolation) metastable oligomeric aluminium hydroxides and oxo-hydroxides are formed [28]. By further polycondensation of the oligomeric alumina species under controlled conditions, a phase transition from sol to gel can be achieved in a controlled environment $\left(20 \mathrm{~min}\right.$ in closed vessels at $\left.40{ }^{\circ} \mathrm{C}\right)$.

Scheme 1. Hydrolysis reaction of aluminium precursor.

$$
\left[\mathrm{Al}\left(\mathrm{H}_{2} \mathrm{O}\right)_{6}\right]^{3+}+\mathrm{n} \mathrm{H}_{2} \mathrm{O} \rightleftharpoons\left[\mathrm{Al}\left(\mathrm{H}_{2} \mathrm{O}\right)_{6-\mathrm{n}}(\mathrm{OH})_{\mathrm{n}}\right]^{(3-\mathrm{n})+}+\mathrm{n} \mathrm{H}_{3} \mathrm{O}^{+}
$$

Figure 5. Photograph of the alumina monolith after calcination at $500{ }^{\circ} \mathrm{C}$ and the corresponding SEM pictures showing its isotropic and homogeneous macroporous network (macropores $\sim 1 \mu \mathrm{m}$ ) and its skeleton (thickness $\sim 1 \mu \mathrm{m}$ ).

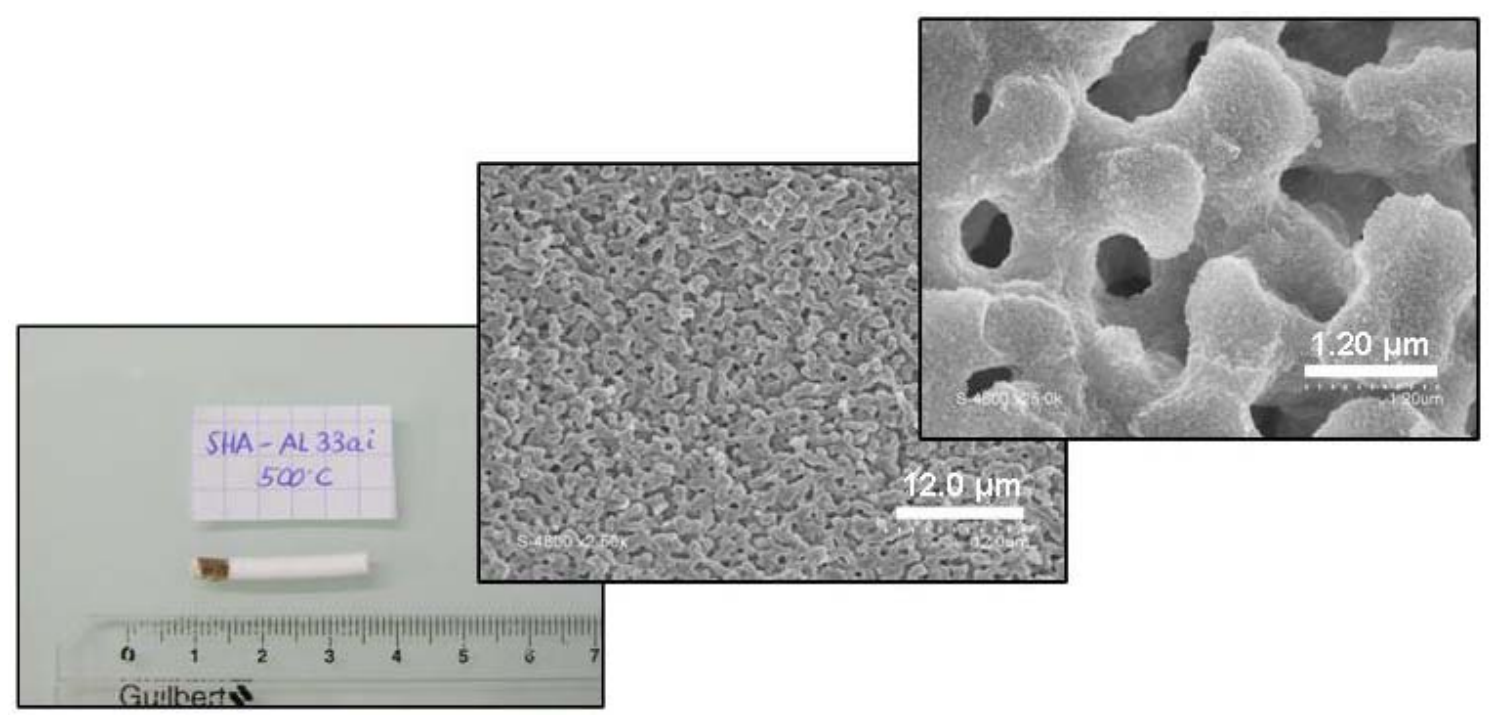

The aim of the synthesis is the fabrication of hierarchically porous monoliths exhibiting a continuous macroporous morphology and a further porosity on a different length scale such as mesoporosity. Thus, a phase-separation inducing agent such as PEO, which is a highly hydrophilic polymer, is employed to generate a continuous morphology in the micrometer range. It is known from the synthesis of hierarchically organized $\mathrm{SiO}_{2}$ monoliths that with increasing size of the polymerizing $\mathrm{SiO}_{2}$ oligomers, the miscibility of the polar solvent-rich and the less polar polymer-rich phase (enhanced polycondensation of $\mathrm{SiO}_{2}$ oligomers due to agglomeration at the ethylene oxide units of the PEO via hydrogen bonding) is gradually reduced and phase separation occurs. This phase separation is then subsequently frozen by sol-gel transition. If the phase separation occurs via spinodal decomposition, the resulting morphology consists of bi-continuous domains with diffused interfaces, which only after further solidification of the silica network evolve sharp solid/liquid interfaces [31,32]. It is highly assumed that a similar mechanism also occurs for the alumina system [28,33]. 
Figure 6. SEM images exhibiting the impact of the varying molar ratio of PEO $\left(\mathrm{M}_{\mathrm{V}}=10^{6}\right)$ on the resulting morphologies in the micrometre range $(\mathbf{A}) \mathrm{Al} / \mathrm{PEO}=1 / 3.9 \times 10^{-6}$; (B) $\mathrm{Al} / \mathrm{PEO}=1 / 4.5 \times 10^{-6} ;(\mathbf{C}) \mathrm{Al} / \mathrm{PEO}=1 / 5.1 \times 10^{-6}$.
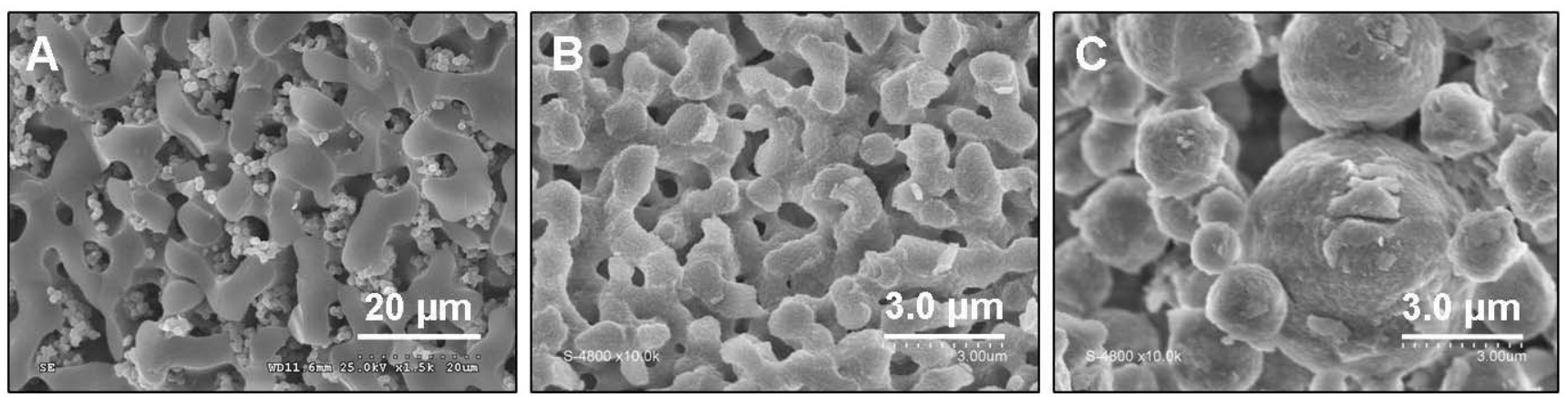

This synthesis is very sensitive and we show in Figure 6 that even slight changes in the molar ratio of $\mathrm{Al} / \mathrm{PEO}$ have a major influence on the resulting macroporous morphology from bi-continuous to particulate as proven by the SEM images (Figure 6). A highly bi-continuous alumina skeleton was obtained with $\mathrm{Al} / \mathrm{PEO}$ ratio to $1 / 4.5 \times 10^{-6}$, whereas an agglomerate of particles was obtained for $\mathrm{Al} / \mathrm{PEO}$ ratio to $1 / 5.1 \times 10^{-6}$.

Figure 7. (A) Typical $\mathrm{N}_{2}$ sorption isotherm at $77 \mathrm{~K}$ for alumina monoliths and (B) ${ }^{27} \mathrm{Al}$ MAS NMR spectra recorded at a steady spin rate of $10 \mathrm{kHz}$ of an alumina monolith $\left(\mathrm{Al} / \mathrm{PEO}=1 / 5.1 \times 10^{-6}\right)$.
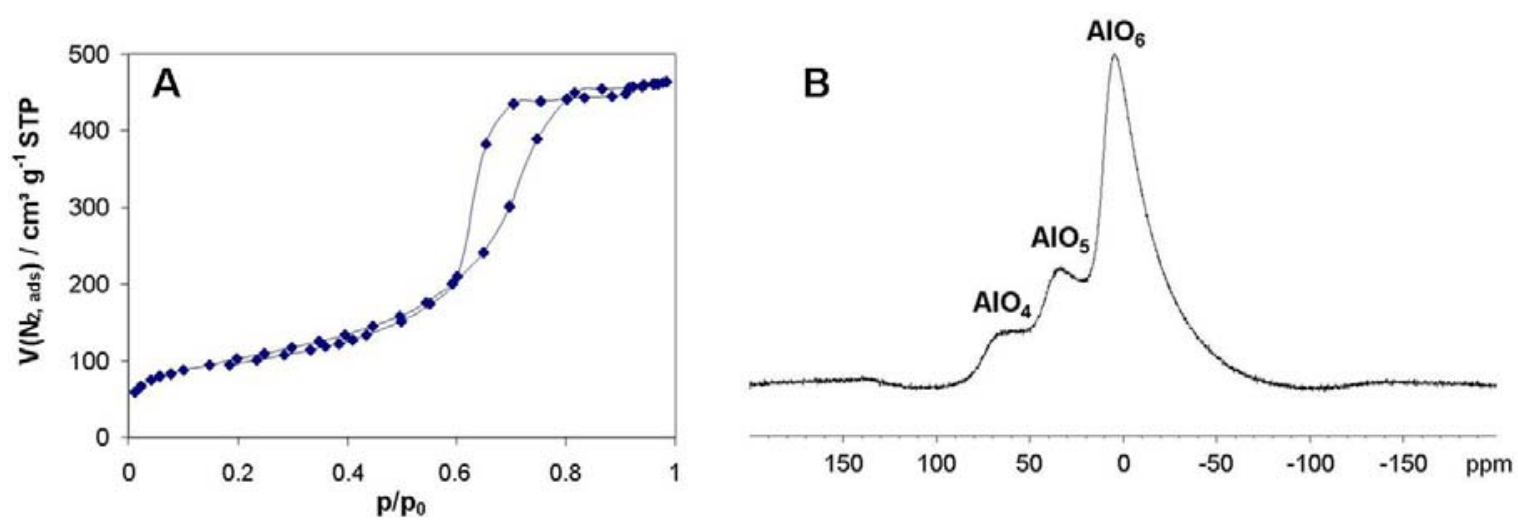

The corresponding nitrogen sorption isotherms (Figure 7A) of all alumina monoliths (Table 1) exhibit a high surface area $\left(\sim 400 \mathrm{~m}^{2} \mathrm{~g}^{-1}\right)$, a large pore volume $\left(0.7 \mathrm{~mL} \mathrm{~g}^{-1}\right)$, a quite narrow mesopore size distribution $(\sim 7 \mathrm{~nm})$ for the mesopore system resulting from interparticulate voids existing between the nanoparticles forming the monolith skeleton. It is known from XRD investigations that the alumina phase is completely amorphous after calcination of the monolith at $500{ }^{\circ} \mathrm{C}$ in air, exhibiting besides octahedral $\mathrm{AlO}_{6}$-sites also $\mathrm{AlO}_{4}$ and $\mathrm{AlO}_{5}$ (tetra- and pentahedral coordinated) species (Figure 2B).

The main drawback of this procedure is the difficulty to control the parameters of the synthesis, the large shrinkage of the monolith upon synthesis (from $8 \mathrm{~mm}$ in the mold to $3 \mathrm{~mm}$ after synthesis), and the high temperature needed to get the $\gamma-\mathrm{Al}_{2} \mathrm{O}_{3}$ phase $\left(500{ }^{\circ} \mathrm{C}\right.$ is not enough), but this represents the only example to synthesize an alumina monolith with hierarchical porosity suitable for continuous flow application [18]. 
Table 1. Textural properties of alumina monoliths obtained with different Al/PEO ratios.

\begin{tabular}{cccc}
\hline & \multicolumn{3}{c}{$\mathbf{N}_{\mathbf{2}}$-sorption } \\
\hline $\mathbf{A l} / \mathbf{P E O}$ & $\mathbf{S}_{\mathbf{B E T}} / \mathbf{m}^{\mathbf{2}} \mathbf{g}^{\mathbf{- 1}}$ & $\mathbf{D}_{\mathbf{B d B}} / \mathbf{n m}$ & $\mathbf{V}_{\mathbf{p}} / \mathbf{c m}^{\mathbf{3}} \mathbf{g}^{\mathbf{- 1}}$ \\
\hline $1 / 3.9 \times 10^{-6}$ & 56 & - & 0.4 \\
$1 / 4.5 \times 10^{-6}$ & 364 & 7.0 & 0.7 \\
$1 / 5.1 \times 10^{-6}$ & 313 & 7.0 & 0.6 \\
\hline
\end{tabular}

Table 2. Comparison of the textural properties of the mesoporous alumina $\left(\gamma-\mathrm{Al}_{2} \mathrm{O}_{3}\right)$ prepared by different routes.

\begin{tabular}{cccc}
\hline & \multicolumn{3}{c}{$\mathbf{N}_{\mathbf{2}}$-sorption } \\
\hline $\boldsymbol{\gamma}-\mathbf{A l}_{\mathbf{2}} \mathbf{O}_{\mathbf{3}}$ & $\mathbf{S}_{\mathbf{B E T}} / \mathbf{m}^{\mathbf{2}} \mathbf{g}^{\mathbf{- 1}}$ & $\mathbf{D}_{\mathbf{B d B}} / \mathbf{n} \mathbf{m}$ & $\mathbf{V}_{\mathbf{p}} / \mathbf{c m}^{\mathbf{3}} \mathbf{g}^{\mathbf{- 1}}$ \\
\hline Rapid and easy sol-gel & 338 & 11.0 & 1.10 \\
Nanostructured alumina (EISA) & 197 & 8.6 & 0.38 \\
Macro-/mesoporous Monolith & 364 & 7.0 & 0.70 \\
\hline
\end{tabular}

\section{Experimental Section}

\subsection{Chemicals}

Block-poly(ethylene oxide)-block-poly(propylene oxide)-block-poly(ethylene oxide) (P123, $\left.\mathrm{M}_{\mathrm{av}}=5,800, \mathrm{EO}_{20} \mathrm{PO}_{70} \mathrm{EO}_{20}\right)$, poly(ethylene oxide) (PEO, $\left.\mathrm{M}_{\mathrm{av}}=1,000,000\right)$, dodecylamine (DDA), 2-butoxyethanol, and ( \pm )-propylene oxide (PO) were purchased from Sigma-Aldrich. The precursors $\mathrm{AlCl}_{3} \cdot 6 \mathrm{H}_{2} \mathrm{O}, \mathrm{Al}(\mathrm{Osec} \mathrm{Bu})_{3}$, and $\mathrm{Al}(\mathrm{O} i \mathrm{Pr})_{3}$ as well as all employed solvents (ethanol, butan-2-ol, etc.) and acids $\left(\mathrm{HNO}_{3}, 68 \%\right)$ were purchased from Sigma-Aldrich and were used without further purification.

\subsection{Materials Synthesis}

\subsubsection{Nanostructured Mesoporous Amorphous $\mathrm{Al}_{2} \mathrm{O}_{3}$ Powders}

In a modified synthesis based on the synthesis procedure presented by Yuan et al. [20] the precursor $\mathrm{Al}(\mathrm{O} i \mathrm{Pr})_{3}$ was added dropwise to a pre-homogenized solution of $\mathrm{P} 123$ in EtOH and $\mathrm{HNO}_{3}$ under vigorous stirring at room temperature (RT). The molar ratio of the synthesis mixture was adjusted to 1:0.017:34.1:2.09 $\mathrm{Al}(\mathrm{O} i \mathrm{Pr})_{3} / \mathrm{P} 123 / \mathrm{EtOH} / \mathrm{HNO}_{3}$. The sol was stirred for $5 \mathrm{~h}$ at $\mathrm{RT}$ before it was transferred to an oven with ventilation at $60{ }^{\circ} \mathrm{C}$ for 2 days to introduce the evaporation-induced self-assembly in order to obtain a 2D-hexagonally nanostructured mesoporous alumina network and for a subsequent drying of the final material. Without a further washing step, the incorporated polymer was eliminated by calcination at $400{ }^{\circ} \mathrm{C}$ in a tubular furnace under air flow with a heating ramp of $1{ }^{\circ} \mathrm{C} \min ^{-1}$ for $4 \mathrm{~h}$.

\subsubsection{Disordered Mesoporous $\gamma-\mathrm{Al}_{2} \mathrm{O}_{3}$ Powders}

Disordered mesoporous $\mathrm{Al}_{2} \mathrm{O}_{3}$ powders exhibiting high specific surface areas were synthesized by a new precipitation strategy in 2-butoxyethanol. In a beaker $\mathrm{Al}(\mathrm{Osec} \mathrm{Bu})_{3}$ was combined with 2-butoxyethanol to prevent early hydrolysis and condensation of precursor. An aqueous solution of 
dodecylamine (DDA) in 2-butoxyethanol (2-BuOEt) was slowly added (within $20 \mathrm{~min}$ ) under vigorous stirring at RT. During the addition of the aqueous phase, first a gel was formed which was then destroyed by further addition of the aqueous phase resulting in a precipitation of alumina. The molar ratio of the sol was 1:0.04:5.27:17.00 $\mathrm{Al}(\mathrm{Osec} \mathrm{Bu})_{3} / \mathrm{DDA} / \mathrm{H}_{2} \mathrm{O} / 2-\mathrm{BuOEt}$. The resulting precipitate was aged for $24 \mathrm{~h}$ at $33{ }^{\circ} \mathrm{C}$, filtrated and washed 3 times with $\sec \mathrm{BuOH}$ at $\mathrm{RT}$. The resulting alumina powders were first dried at $80{ }^{\circ} \mathrm{C}$ for 1 day before they were calcined at $500{ }^{\circ} \mathrm{C}$ for $5 \mathrm{~h}$ in air (heating ramp: $2{ }^{\circ} \mathrm{C} \min ^{-1}$ ).

\subsubsection{Hierarchically Macro-/Mesoporous Alumina Monoliths}

Hierarchical alumina monoliths were prepared via a modified synthesis pathway based on the preparation given by Tokudome and Nakanishi [28,33] by employing $\mathrm{AlCl}_{3} \cdot 6 \mathrm{H}_{2} \mathrm{O}$ as precursor. PEO $(0.08 \mathrm{~g})$ were first dissolved in $5.5 \mathrm{~mL}$ Ethanol and $4.0 \mathrm{~mL} \mathrm{H}_{2} \mathrm{O}\left(58: 42 \mathrm{v} / \mathrm{v} \mathrm{EtOH} / \mathrm{H}_{2} \mathrm{O}\right)$ at $0{ }^{\circ} \mathrm{C}$. Only after complete dissolution of $\mathrm{PEO}, 4.32 \mathrm{~g} \mathrm{AlCl} \mathrm{Al}_{3} \cdot 6 \mathrm{H}_{2} \mathrm{O}$ were added under vigorous stirring at $0{ }^{\circ} \mathrm{C}$. For complete dissolution of the aluminium salt, the reaction mixture was then maintained at $25{ }^{\circ} \mathrm{C}$ in an oil-bath and $3.8 \mathrm{~mL}$ propylene oxide (PO) was quickly added. Within 3 minutes the $\mathrm{pH}$ of the sol raised from 1 to 3 and the sol was transferred to vessels. The vessels were sealed and the system was allowed to gel and age at $40{ }^{\circ} \mathrm{C}$ for 2 days. After $20 \mathrm{~min}$ at $40{ }^{\circ} \mathrm{C}$, the sol-gel transition as well as a macroscopic phase separation could be observed, resulting in turbid gel bodies.

After aging, all gels were washed in 2-propanol at $60{ }^{\circ} \mathrm{C}(4 \times$ solvent exchange within $6 \mathrm{~h})$ before they were slowly dried from RT to $40{ }^{\circ} \mathrm{C}$ within 7 days. The monoliths were calcined from RT to $500{ }^{\circ} \mathrm{C}$ with intermediate heating plateaus at $100{ }^{\circ} \mathrm{C}$ and $250{ }^{\circ} \mathrm{C}$. Each temperature was held for $5 \mathrm{~h}$ and the heating ramp between the plateaus was $1^{\circ} \mathrm{C} \mathrm{min}^{-1}$.

\subsection{Characterization}

All samples were characterized by nitrogen sorption analyses. The adsorption-desorption isotherms of the calcined samples were measured on a Micromeritics ASAP 2010 device at $77 \mathrm{~K}$. All samples were degassed at either 150 or $250{ }^{\circ} \mathrm{C}$ in vacuum for $8 \mathrm{~h}$ prior to the analysis. The specific surface area was determined by the BET method for adsorption data in the relative pressure range from 0.05 to 0.20 [34]. The pore volumes were calculated from the quantity of nitrogen adsorbed at a relative pressure of 0.97 . Average pore diameters were determined from the nitrogen desorption branch according to Broekhoff and de Boer (BdB) [35,36].

Powder X-ray diffraction (XRD) patterns were recorded on a Bruker AXS D8 Diffractometer by using $\mathrm{CuK} \alpha$ radiation and a $\mathrm{Ni}$ monochromator.

The macroporous morphology of the monoliths and the particle morphology were examined on a Hitachi S-4500 I Scanning Electron Microscope (SEM).

All ${ }^{27}$ Al Magic Angle Spinning NMR spectra were recorded on a Bruker DSX-300 spectrometer operating at $78.2 \mathrm{MHz}$ and a spinning rate of $10 \mathrm{kHz}$. A single pulse sequence with a short pulse length of $0.5 \mu \mathrm{s}$ was employed and a delay of $1.0 \mathrm{~s}$ allowed the complete relaxation. For one spectrum 1000 scans were accumulated. 


\section{Conclusions}

Today a wide variety of different synthesis strategies are proposed to obtain mesoporous alumina materials. The synthesis has to be chosen depending on the required properties such as ordered mesoporosity, high specific surface areas and pore volumes, crystallinity, hierarchical structures, etc. In this paper we have presented the most convenient strategies in order to fabricate reproducible mesoporous alumina materials with tailored properties (summary in Table 2). For theoretical studies the use of hexagonal ordered alumina is the most suitable and this synthesis is reached using a triblock-copolymer surfactant in acidic media by the Evaporation Induced Self-Assembly. However, this synthesis is difficult to scale up for industrial applications as catalytic support. If large scale synthesis of mesoporous alumina with high specific surface areas and pore volumes is requested, the precipitation process in 2-butoxyethanol has proven to be a very convenient strategy with respect to reproducibility, cost-effectiveness, reaction time, energy input and prices for the educts. For the transfer from particulate to macro-/mesoporous monolithic alumina materials only few synthesis procedures are described in the literature until today. The procedure published by Nakanishi et al. [28,31-33] is the most promising. The bi-continuous macroporous morphology obtained in this preparation of alumina monoliths is proper for high mass transfer and the high specific surface area is suitable for high loadings of reactive catalytic species. These monoliths are therefore very attractive support materials for applications in continuous flow.

\section{Acknowledgments}

The research leading to these results has received funding from European Community's Seventh Framework Program through the Marie-Curie Initial Training Network NANO-HOST (Grant Agreement ITN 215193-2).

\section{References}

1. Marques-Alvarez, C.; Zilkova, N.; Perez-Pariente, J.; Cejka, J. Synthesis, characterization and catalytic applications of organized mesoporous aluminas. Catal. Rev. 2008, 50, 222-286.

2. Liu, H.; Lu, G.; Guo, Y.; Wang, Y.; Guo, Y. Synthesis of mesoporous $\mathrm{Pt} / \mathrm{Al}_{2} \mathrm{O}_{3}$ catalysts with high catalytic performance for hydrogenation of acetophenone. Catal. Commun. 2009, 10, 1324-1329.

3. Prins, R.; de Beer, V.H.; Somorjai, G.A. Structure and function of the catalyst and the promoter in Co-Mo hydrodesulfurization. Catal. Rev. Sci. Eng. 1989, 31, 1-41.

4. Bejenaru, N.; Lancelot, C.; Blanchart, P.; Lamonier, C.; Rouleau, L.; Payen, E.; Dumeignil, R.S. Synthesis, characterization, and catalytic performances of novel CoMo hydrodesulfurization catalysts supported on mesoporous aluminas. Chem. Mater. 2009, 21, 522-533.

5. Blin, J.-L.; Léonard, A.; Yuan, Z.-Y.; Gigot, L.; Vantomme, A.; Cheetham, A.K.; Su, B.-L. Hierarchically mesoporous/macroporous metal oxides templated from polyethylene oxide surfactant assemblies. Angew. Chem. Int. Ed. 2003, 42, 2872-2875. 
6. Bai, P.; Wu, P.; Yan, Z.; Zhao, X.S. A reverse cation-anion double hydrolysis approach to the synthesis of mesoporous $\gamma-\mathrm{Al}_{2} \mathrm{O}_{3}$ with a bimodal pore size distribution. Micropor. Mesopor. Mater. 2009, 118, 288-295.

7. Groen, J.C.; Zhu, W.; Brouwer, S.; Huynink, S.J.; Kapteijn, F.; Moulijn, J.A.; Pérez-Ramírez, J. Direct demonstration of enhanced diffusion in mesoporous ZSM-5 zeolite obtained via controlled desilication. J. Am. Chem. Soc. 2007, 129, 355-360.

8. Bagshaw, S.A.; Prouzet, E.; Pinnavaia, T.J. Templating of mesoporous molecular sieves by nonionic polyethylene oxide surfactants. Science 1995, 269, 1242-1244.

9. Tian, B.; Liu, X.; Tu, B.; Yu, C.; Fan, J.; Wang, L.; Xie, S.; Stucky, G.D.; Zhao, D. Self-adjusted synthesis of ordered stable mesoporous minerals by acid-base pairs. Nature Mater. 2003, 2, 159-163.

10. Wu, Q.; Zhang, F.; Yang, J.; Li, Q.; Tu, B.; Zhao, D. Synthesis of ordered mesoporous alumina with large pore sizes and hierarchical structure. Micropor. Mesopor. Mater. 2011, 143, 406-412.

11. Liu, Q.; Wang, A.Q.; Wang, X.D.; Zhang, T. Ordered crystalline alumina molecular sieves synthesized via a nanocasting route. Chem. Mater. 2006, 18, 5153-5155.

12. Hao, Z.; Liu, H.; Guo, B.; Li, H.; Zhang, J.-W.; Gan, L.-H.; Xu, Z.-J.; Chen, L.-W. Sol-gel synthesis of alumina using inorganic salt precursor. Acta Phys. Chim. Sin. 2007, 23, 289-294.

13. Baumann, T.F.; Gash, A.E.; Chinn, S.C.; Sawvel, A.M.; Maxwell, R.S.; Satcher, J.H. Synthesis of high-surfacearea alumina aerogels without the use of alkoxide precursors. Chem. Mater. 2005, 17, 395-301.

14. Yao, N.; Xiong, G.; Zhang, Y.; He, M.; Yang, W. Preparation of novel uniform mesoporous alumina catalyst by the sol-gel method. Catal. Today 2001, 68, 97-109.

15. Yuan, Z.-Y.; Ren, T.-Z.; Azioune, A.; Pireaux, J.-J.; Su, B.-L. Self-assembly of hierarchically mesoporous-macroporous phosphated nanocrystalline aluminum (oxyhydr)oxide materials. Chem. Mater. 2006, 18, 1753-1767.

16. Dacquin, J.-P.; Dhainaut, J.; Duprez, D.; Royer, S.; Lee, A.F.; Wilson, K. An efficient route to highly organized, tunable macroporous-mesoporous alumina. J. Am. Chem. Soc. 2009, 131, 12896-12897.

17. El Kadib, A.; Chimenton, R.; Sachse, A.; Fajula, F.; Galarneau, A.; Coq, B. Functionalized inorganic monolithic microreactors for high productivity in fine chemicals catalytic synthesis. Angw. Chem. Int. Ed. 2009, 77, 5069-5072.

18. Sachse, A.; Galarneau, A.; Fajula, F.; Di Renzo, F.; Creux, P.; Coq, B. Functional silicic monoliths with hierarchical uniform porosity for catalysis under flow. Microporous Mesoporous Mater. 2011, 140, 58-68.

19. Sachse, A.; Galarneau, A.; Coq, B.; Fajula, F. Monolithic flow microreactors improve fine chemicals synthesis. New. J. Chem. 2011, 35, 259-264.

20. Yuan, Q.; Yin, A.-X.; Luo, C.; Sun, L.-D.; Zhang, Y.-W.; Duan, W.-T.; Liu, H.-C.; Yan, C.-H. Facile synthesis of ordered mesoporous $\gamma$-aluminas with high thermal stability. J. Am. Chem. Soc. 2008, 130, 3465-3472.

21. Zhang, W.; Pinnavaia, T.J. Rare earth stabilization of mesoporous alumina molecular sieves assembled through an $\mathrm{N}^{\circ} \mathrm{I}^{\circ}$ pathway. Chem. Comm. 1998, 1185-1186.

22. Zhang, W.; Pinnavaia, T.J. Mesostructured $\gamma-\mathrm{Al}_{2} \mathrm{O}_{3}$ with a lathlike framework morphology. J. Am. Chem. Soc. 2002, 124, 12294-12301. 
23. Boissière, C.; Nicole, L. Gervais, C.; Bobonneau, F.; Antonietti, M.; Amenitsch, H.; Sanchez, C.; Grosso, D. Nanocrystalline mesoporous $\gamma$-alumina powders "UPMC1 Material" gathers thermal and chemical stability with high surface area. Chem. Mater. 2006, 18, 5238-5243.

24. Niesz, K.; Yang, P.; Somorjai, G.A. Sol-gel synthesis of ordered mesoporous alumina. Chem. Comm. 2005, 1986-1987.

25. Yang, P.; Zhao, D.; Margolese, D.I.; Chmelka, B.F.; Stucky, G.D. Generalized syntheses of large-pore mesoporous metal oxides with semicrystalline frameworks. Nature 1998, 396, 152-155.

26. Morris, S.M.; Fulvio, P.F.; Jaroniec, M. Ordered mesoporous alumina-supported metal oxides. J. Am. Chem. Soc. 2008, 130, 15210-15216.

27. Dacquin, J.P.; Dhainaut, J.; Duprez, D.; Royer, S.; Lee, A.F.; Wilson, K. An efficient route to highly organized, tunable macroporous-mesoporous alumina. J. Am. Chem. Soc. 2009, 131, 12896-12897.

28. Tokudome, Y.; Nakanishi, K.; Kanamori, K.; Fujita, K.; Akamatsu, H.; Hanada, T. Structural characterization of hierarchically porous alumina aerogel and xerogel monoliths. J. Colloid Interfac. Sci. 2009, 338, 506-513.

29. Li, L.L.; Duan, W.-T.; Yuan, Q.; Li, Z.-X.; Duan, H.-H.; Yan, C.-H. Hierarchical $\gamma-\mathrm{Al}_{2} \mathrm{O}_{3}$ monoliths with highly ordered $2 \mathrm{D}$ hexagonal mesopores in macroporous walls. Chem. Commun. 2009, 41, 6174-6176.

30. Brinker, C.J.; Scherer, G.W. Sol-Gel Science: The Physics and Chemistry of Sol-Gel Processing; Academic Press: San Diego, CA, USA, 1990.

31. Nakanishi, K. Pore structure control of silica gels based on phase separation. J. Porous Mater. 1997, 4, 67-112.

32. Nakanishi, K. Sol-gel process of oxides accompanied by phase separation. Bull. Chem. Soc. Jpn. 2006, 79, 673-691.

33. Tokudome, Y.; Fujita, K.; Nakanishi, K.; Miura, K.; Hirao, K. Synthesis of monolithic $\mathrm{Al}_{2} \mathrm{O}_{3}$ with well-defined macropores and mesostructured skeletons via the sol-gel process accompanied by phase separation. Chem. Mater. 2007, 19, 3393-3398.

34. Brunauer, S.; Emmett, P.H.; Teller, E. Adsorption of gases in multimolecular layers. J. Am. Chem. Soc. 1938, 60, 309-319.

35. Broekhoff, J.C.P.; De Boer, J.H. Studies on pore systems in catalysts: XIV. Calculation of the cumulative distribution functions for slit-shaped pores from the desorption branch of a nitrogen sorption isotherm. J. Catal. 1968, 10, 377-390.

36. Galarneau, A.; Desplantier, D.; Dutartre, R.; di Renzo, F. Micelle-templated silicates as a test bed for methods of mesopore size evaluation. Mesoporous Mater. 1999, 27, 297-308.

(C) 2012 by the authors; licensee MDPI, Basel, Switzerland. This article is an open access article distributed under the terms and conditions of the Creative Commons Attribution license (http://creativecommons.org/licenses/by/3.0/). 